\title{
EXPERIMENTAL INVESTIGATION AND ANALYSIS OF EDM WITH SILICON OIL AS DIELECTRIC FLUID
}

\begin{tabular}{|c|c|}
\hline $\begin{array}{c}\text { Lokesh Upadhyay }^{\mathbf{a}} \\
\text { Department of Mechanical Engineering }^{\mathrm{a}} \\
\text { Sachdeva Institute of Technology, Farah }^{\mathrm{a}} \\
\text { Mathura, India } \\
\text { Email - erlokup@ @mail.com }{ }^{\mathrm{a}}\end{array}$ & $\begin{array}{c}\text { M. L Agrawal }{ }^{\mathbf{b}} \text {, P.M Pandey } \\
{ }^{\mathrm{b}} \text { Department of Mechanical Engineering } \\
\text { YMCAUST Faridabad, India } \\
{ }^{\mathrm{c}} \text { Indian Institute of Technology Delhi, India }\end{array}$ \\
\hline
\end{tabular}

\begin{abstract}
-
The aim of this paper to reveal the process parameter that affect the material removal rate and surface finish of EDM process by using silicon oil as dielectric fluid. In this study we proposed a novel method of EDM that used silicon oil instead of conventional oil like kerosene. As a result of which the process becomes more stable and material removal rate and surface finish improved. The EDM process is mainly used for making dies, moulds, and parts of aerospace, automotive industries. It is difficult to produce high material removal rate with good surface finish in case of electrical discharge machining of hard materials. We have found increment in material removal rate and surface roughness due to deeper and larger craters by using silicon oil as die electric fluid. Duty cycle was the most effecting factor in case of material removal rate and discharge current was the most affecting factor in case of surface roughness. The four process parameters discharge current, pulse on time, duty cycle and gap voltage were used in this study.
\end{abstract}

Keywords: Electrical discharge machining, Material removal rate, Surface roughness, Silicon oil.

\section{INTRODUCTION}

Electrical discharge machining (EDM) is one of the extensively used nonconventional material removal processes. EDM is a process that is based on removing material from a conducting workpiece by means of series of repeated electrical discharges between tool electrode (cathode) and workpiece (anode) in the presence of dielectric fluid. The electrode is moved towards the workpiece by servo controlled feed until the gap is small enough in the range of 10-100 $\mu \mathrm{m}$ [1]. Thermal energy generate a channel of plasma between the cathode and anode at a temperature range of 8000 to $20000^{\circ} \mathrm{C}$ initializing a substantial amount of heating and melting of material at a surface of each pole [2]. There are so many di electric fluids are available for electrical discharge machining like kerosene, paraffin's oil etc [3]. The most widely used types of EDM are die sinking EDM and wire EDM. Die sinker EDM is widely used in the mould making industries. The advent of computer numerical control in EDM brought tremendous advances in improving the efficiency of the machining operation [4, 5]. However major challenges in EDM process are low arc stability, electrode wear rate, low material removal rate, arcing and surface finish. A few researchers have attempted to improve the process performance with limited success $[6,10]$. The objective of this paper is to investigate the optimal process parameter on electric discharge machine on M2 high speed steel workpiece with copper as a tool electrode. The effect of various process parameters on machining is investigated in this paper. It is characterized by its improved metal removal rate and better surface finish. The input process parameters are discharge current, pulse on time, duty cycle, gap voltage are used for experimental work and their effect on material removal rate and surface roughness $[11,12]$.

\section{EXPERIMENTAL DETAIL}

Die sinking EDM experiments have been carried out on EDM machine (model sparkonix, India). In all experiment, silicon has been used as dielectric fluid. Total 31 experiments have been performed using CCRD with independent variables at 5 different levels. Machining time for each experiment has been kept 60 minutes. After EDM, M2 grade high speed steel workpiece is cleaned with acetone. A high precision electronic weighing balance with least count $0.01 \mathrm{mg}$ has been used to measure the weight loss of workpiece after each experiment. The surface finish after machining was measured by using Talysurf 6 (Rank Taylor Hobson, England). A traverse length of $3 \mathrm{~mm}$ with a cut-off evaluation length of $2 \mathrm{~mm}$ was used. The centre line average value of surface roughness is most widely used surface roughness parameter in industry, was selected in this study. Each sample was measured three times and the average was taken as the response. MRR has been defined as the ratio of wear weight of workpiece to the machining time.

\subsection{Selection of tool and workpiece}

M2 grade high speed steel workpieces have been spark eroded using copper as tool material. The workpiece used for this study was high speed steel having dimensions $30 * 30 * 10 \mathrm{~mm}^{3}$. The hardness of the workpiece was $35 \mathrm{HRC}$. The copper tool of $9 \mathrm{~mm}$ diameter was used in this study. The silicon oil used as di electric fluid with viscosity of $10 \mathrm{cst}$.

\subsection{Process Parameters}

There were four process parameters with the five levels to investigate the response variables. Table 1 shows the process parameters along with the level of process parameters. 
Table 1 process parameter and its level

\begin{tabular}{|c|c|c|c|c|c|c|}
\hline \multirow{2}{*}{ Factors } & \multirow{2}{*}{ Units } & \multicolumn{5}{|c|}{ Lerels } \\
\cline { 3 - 7 } & & -2 & -1 & 0 & 1 & 2 \\
\hline Discharge current & A & 3 & 4 & 5 & 6 & 7 \\
\hline Pulse-on time & (us) & 100 & 200 & 300 & 400 & 500 \\
\hline Duty cycle & & 0.60 & 0.66 & 0.72 & 0.78 & 0.88 \\
\hline Gap voltage & (V) & 50 & 55 & 60 & 65 & 70 \\
\hline
\end{tabular}

\subsection{Response Variables}

There were two response variables, material removal rate and surface roughness which were subjected to investigate during the machining at various levels of process parameters.

\subsection{Experimental setup}

An acrylic box has been prepared of dimensions $25 * 25 * 25 \mathrm{~cm}^{3}$ for experimental purpose and a pump of dessert cooler was used for flushing of fluid on the workpiece. The arrangement is shown in fig. $(a, b)$

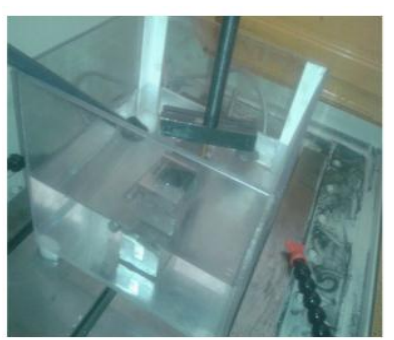

Fig (a)

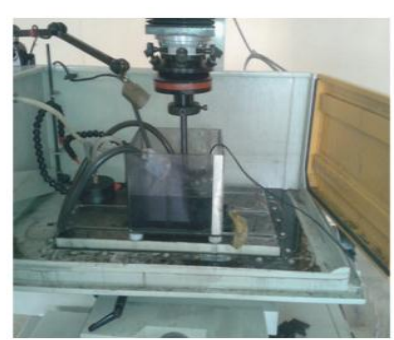

Fig (b)

\section{RESULTS AND DISCUSSION}

The study focus to know what effect of process parameter on material removal rate and surface roughness in presence of silicon oil used as di electric fluid.

\subsection{Material removal rate}

The effect of different process parameter on MRR can be explained with the help of ANNOVA. It is observed that duty cycle was most effecting factor in comparision to other parameters. The effect of gap voltage is negligible on MRR. Percentage contribution of each term of the model for surface roughness is shown in fig.

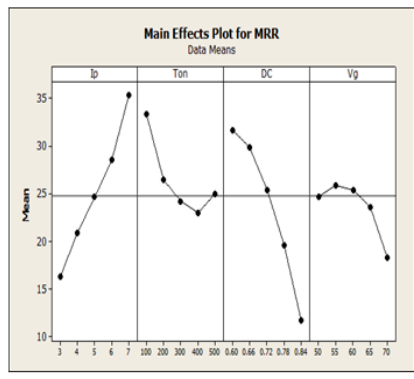

Fig (c) Main effect for MRR

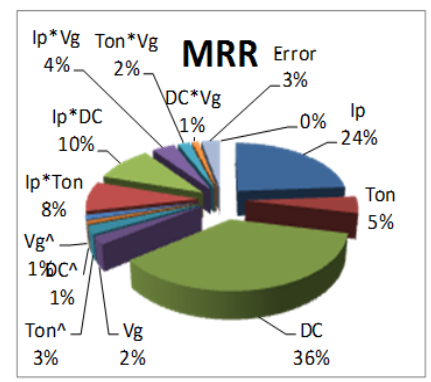

Fig (d) Percentage contribution of the factors on MRR for EDM
- $\quad$ MRR increases with the increase in discharge current. This could be due to an increase in both diameter and depth of crates as well as discharge energy at the discharge point to improve the rate of melting and evaporation.

In fig. (c) Shows that MRR decreases with increase in pulse on time $\left(\mathrm{T}_{\mathrm{on}}\right)$ initially but after a certain value of pulse on time, MRR increases. This is due to fact that, with an increase in pulse on time, some of melted material resolidifies on the workpiece due to lower discharge energy initially, which leads to decrease in MRR. However beyond the certain value of pulse on time, an increase in discharge energy conducted into machining gap and within a single discharge causes the MRR to increase.

- $\quad$ It can be seen that an increase in the duty cycle leads to increase of the MRR. The increase of duty cycle means applying the discharge for a longer duration and this cause an increase in MRR.

\subsection{Surface roughness}

For surface roughness it is observed that discharge current was most affected the surface roughness in comparision to other parameters. The effect of gap voltage was negligible on surface roughness. Percentage contribution for each term of model for surface roughness is shown in figure.

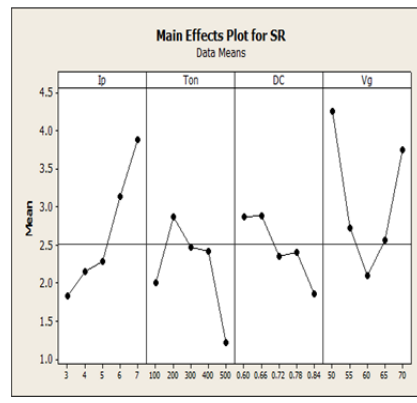

Fig (e) Main effects for SR of EDM

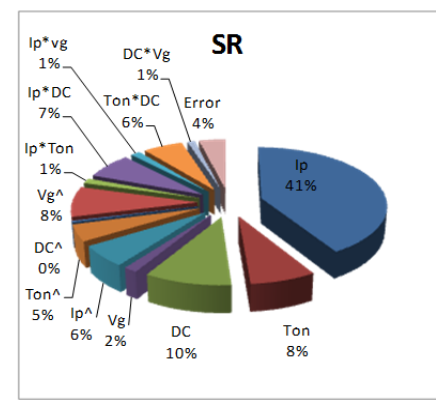

Fig (f) Percentage contribution of the factors on SR for EDM
- An increase in discharge current increases the surface roughness. The discharge energy density and the impulsive force increase with discharge current and results deeper and larger discharge craters. It increases both MRR and SR. 
- However, the small improvement in surface finish has been observed beyond discharge current $6 \mathrm{~A}$. This may be due to the presence of sufficient amount of metal particles in form of debris in dielectric which modify the plasma channel. Plasma channel is likely to become enlarged and widened. The electric density decreases, hence sparking is uniformly distributed among the powder particles. As a result even and more uniform distribution of the discharge takes place, which causes uniform erosion (shallow crates) on the workpiece. This result in improvement in surface finish.

- An increase in pulse on time increases the surface roughness. This is due to the expansion of plasma channel with an increase in pulse on time which result into wider contact zone of discharging and reduce both energy density and the impulsive force. The melted debris cannot be removed completely due to reduction in impulsive force and forms an apparent globule like recast layer to degrade the surface roughness.

\section{CONCLUSIONS}

Experimental studies were done for material removal rate and surface roughness with silicon oil used as di electric fluid. Based on following study some conclusion are observed

- Material removal rate increases by using silicon oil and duty cycle is the most affecting factor that affect material removal rate by $36 \%$.

- The surface finish is also improving by using silicon oil. Discharge current is the most affecting parameter that affects surface roughness by $41 \%$.

- $\quad$ There is a small improvement in surface finish observed beyond discharge current $6 \mathrm{~A}$. This may be due to the presence of sufficient amount of metal particles in the form of debris in di electric which modify the plasma channel.

\section{Nomenclature}

\begin{tabular}{|ll}
\hline MRR & Material removal rate \\
SR & Surface roughness \\
EDM & Electric discharge machining \\
ANOVA & Analysis of variance \\
$\mathrm{I}_{\mathrm{p}}$ & Peak current \\
$\mathrm{V}_{\mathrm{g}}$ & Gap voltage \\
$\mathrm{T}_{\text {on }}$ & Pulse on time \\
DC & Duty cycle
\end{tabular}

References

[1] G. Boothroyd, W.A. Knight, Fundamentals of Machining and Machine Tools, Taylor \& Francis, Florida, 2006.

[2] K.H. Ho, S.T. Newman, State of the art electrical discharge machining (EDM), International Journal of Machine Tools and Manufacture, 43 (2003) 1287-1300.

[3] N.M. Abbas, D.G. Solomon, M.F. Bahari, A review on current research trends in electrical discharge machining (EDM) International Journal of Machine Tools and Manufacture, 47 (2007) 1214-1228.

[4] A.B. Puri, B. Bhattacharyya, An analysis and optimisation of the geometrical inaccuracy due to wire lag phenomenon in WEDM, International Journal of Machine Tools and Manufacture, 43(2) (2003) 151-159.

[5] K.H. Ho, S.T. Newman, S. Rahimifard, R.D. Allen, State of the art wire electrical discharge machining (EDM), International Journal of Machine Tools and Manufacture, 44 (2004) 1247-1259.

[6] J.R. Crookall, C.J. Heuvelman, Electrodischage machining-the state of the art, Annals of the CIRP, 20(2) (1971) 113-120.

[7] R. Snoeys, F. Van Dyck, Investigation of EDM operation by means of Thermomathematical models, Annals of the CIRP, 21(1) (1971) 35-36.

[8] D.D. Dibitonto, P.T. Eubank, M.R. Patel, M.A. Barrufet, Theoretical models of the electrical discharge machining process.I. A simple cathode erosion model. Journal of the Application Physics 1989, 66 (9), 4095-4103.

[9] M.R. Patel, M.A. Barrufet, P.T. Eubank, D.D. Dibitonto, Theoretical models of the electrical discharge machining process. II. The anode erosion model. Journal of the Application Physics 1989, 66 (9), 4104-4111.

[10] S.M. Pandit, K.P. Rajurkar, A stochastic approach to thermal modeling applied to electrodischarge machining, Journal of Heat Transfer, 105 (1993) 555-561.

[11] K.P. Rajurkar, S.M. Pandit, Quantitative Expressions for some aspects of surface integrity of electro discharge machined components, Journal of Engineering for Industry, 106 (1994) 171177.

[12] S.T. Jilani, P.C. Pandey, Analysis and modeling of EDM parameters, Precision Engineering, 4(4) (1982) 215-221.

[13] J.A. McGeough, Advanced Methods of Machining, Chapman \& Hall, London, 1988.

[14] P.K. Mishra, Nonconventional Machining, Narosa Publishing House, London, 1997

[15] A. Singh, A. Ghosh, A thermo-electric model of material Removal during electric discharge machining, International Journal of Machine Tools and Manufacture, 39(1999) 669 682 . 